\title{
Behçet's disease presenting as bilateral occlusive retinal vasculitis in a young woman
}

\author{
Javeria Muid, ${ }^{1}$ Kirk A J Stephenson 이, ${ }^{1}$ Esraa Hegazy, ${ }^{1}$ Conor C Murphyy ${ }^{1,2}$
}

${ }^{1}$ Department of Ophthalmology, Royal Victoria Eye and Ear Hospital, Dublin, Ireland ${ }^{2}$ Royal College of Surgeons in Ireland, University of Medicine and Health Sciences, Dublin, Ireland

\section{Correspondence to} Dr Kirk A J Stephenson; kirkstephenson@hotmail.com

Accepted 21 February 2021

Check for updates

(c) BMJ Publishing Group Limited 2021. No commercial re-use. See rights and permissions. Published by BMJ.

\begin{tabular}{l}
\hline To cite: Muid J, \\
Stephenson KAJ, Hegazy E, \\
et al. BMJ Case Rep \\
2021;14:e241794. \\
doi:10.1136/bcr-2021- \\
241794 \\
\hline
\end{tabular}

\section{DESCRIPTION}

A 41-year-old white European woman presented with a 4-week history of painless floaters in her left eye and best-corrected visual acuity (BCVA) of 6/6 and 6/30 in right and left eyes, respectively. She had no relevant medical history and was a non-smoker. She reported orogenital ulceration, erythema nodosum, left hand weakness and arthralgia.

Examination showed no anterior segment inflammation or rubeosis. Intraocular pressures were $16 \mathrm{~mm} \mathrm{Hg}$ bilaterally. A left relative afferent pupillary defect was present with +2 vitritis, retinal periphlebitis and inferotemporal branch retinal vein occlusion with macular oedema (figure 1A). Widefield fluorescein angiography (figure 1B) confirmed extensive retinal ischaemia with neovascularisation and collateral blood vessels. Optical coherence tomography confirmed macular oedema (figure 1C).

Serology for rheumatoid factor, anticyclic citrullinated peptide antibodies, antinuclear factor and infectious aetiologies (Mycobacterium tuberculosis, Borrelia burgdorferi, Treponema pallidum and Toxoplasma gondii) was negative. MRI brain revealed cerebral vasculitis. Biopsy of the genital ulceration showed leukocytoclastic vasculitis. Human leucocyte antigen (HLA)-B51 was negative but a diagnosis of Behçet's disease (BD) was made in accordance with International Study Group for Behçet's Disease criteria (ISGBD). She was started on oral prednisolone (50 mg daily) and tacrolimus (2 mg two times per day); however, 11 months later, she had a flare comprising arthritis, cerebral vasculitis and right eye uveitis (figure 2A). Systemic therapy was changed to mycophenolate mofetil and adalimumab with intravitreal antivascular endothelial growth factor and sectoral pan-retinal photocoagulation (PRP) to both eyes. With this immunosuppression regimen, she achieved remission and her BCVA remained 6/6 in both eyes. However, further PRP was required for progressive retinal ischaemia.

$\mathrm{BD}$ is an idiopathic multisystem inflammatory disorder, prevalent along the Silk Road (15-420:100 000), primarily affecting eyes, skin, joints and central nervous system vasculature. ${ }^{1}$ Peak onset is in the third decade; with no gender predilection. ${ }^{2}$ There is ocular involvement in $70 \%$, with $16.6 \%$ of all-cause uveitis attributed to BD. ${ }^{23}$ Hallmark features include oral ulceration (98\%), genital ulceration (80\%-87\%), erythema nodosum (50\%), maculopapular rash (45\%-90\%), positive pathergy test $(8.6 \%-70 \%)$ and ocular inflammation, three of which (particularly recurrent oral ulceration) are required by ISGBD to make a BD



Figure 1 (A) Widefield fundus photograph (Optos 'California', Optos plc, Scotland) of the left eye showing occlusive vasculitis of the inferortemporal retinal vessels. (B) Widefield late phase fluorescein angiogram (FFA) of the left eye confirming extensive ischaemia in the inferior retina with focal leakage from neovascularisation. (C) Macular optical coherence tomography (OCT, Cirrus 5000, Carl Zeiss Meditec, Dublin, USA) scan showing intraretinal oedema. (D) Widefield fundus photograph of the right eye showing similar ischaemia 11 months later. (E) Widefield FFA showing marked ischaemia of the inferior retina. (F) Resolution of left eye oedema on OCT following treatment.

diagnosis. $^{4}{ }^{5}$ HLA-B51 is positive in only $60 \%{ }^{6}$ Classic ophthalmic features are acute anterior uveitis in a white eye with shifting hypopyon, vitritis, occlusive retinal vasculitis, optic disc oedema and retinal neovascularisation. ${ }^{7}$ Sequelae include cataract, glaucoma, optic atrophy and vascular attenuation in end-stage disease. ${ }^{8}$ Treatment aims to induce remission, preventing progressive occlusive retinal vasculitis. Acute sight-threatening uveitis is amenable to high-dose glucocorticoids and/or biological agents (eg, infliximab or interferon alpha). ${ }^{9}$ Remission of posterior uveitis in BD should be maintained with systemic immunosuppression and may require antimetabolites (eg, methotrexate, azathioprine, mycophenolate), calcineurin inhibitors (eg, ciclosporin,

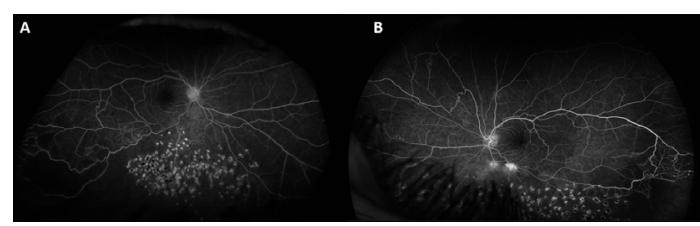

Figure 2 Follow-up widefield FFAs of the right (A) and left (B) eyes showing photocoagulation burns in the inferior retina with progression of retinal ischaemia secondary to occlusive vasculitis and prominent peripheral collateral vessels. FFAs, fluorescein angiography. 
tacrolimus) and/or biological agents (eg, adalimumab, infliximab). ${ }^{9}$ Rituximab has been used for refractory ocular BD with promising short-term results; however, longer follow-up studies are required. ${ }^{10}$ Unilateral exacerbations may benefit from intravitreal corticosteroid therapy adjunctive to systemic treatment. ${ }^{11}$ Despite treatment, legal blindness (ie, BCVA $\leq 6 / 60$ ) occurs in $13 \%$ of eyes of patients with $\mathrm{BD}$, typically due to ischaemic maculopathy. $^{12}$

\section{Learning points}

- Behçet's disease (BD) is an important diagnosis with a 5\% mortality rate by 5-10 years, typically due to vascular events (cardiac or cerebral). Ophthalmic presentation may allow early diagnosis of $\mathrm{BD}$, facilitating treatment and preventing debilitating systemic sequelae.

- Ophthalmic involvement in BD may lead to serious visual morbidity in young patients. Early diagnosis may prevent bilateral blindness and the accompanying loss of quality of life and economic contribution.

- BD should always be considered in the differential diagnosis of any ophthalmic or systemic vasculitis even in areas of low prevalence.

Twitter Kirk A J Stephenson @KarkStaphonsen, Esraa Hegazy @esraahegazy00 and Conor C Murphy @OcularOirg

Acknowledgements The photographic department, Royal Victoria Eye and Ear Hospital, Dublin, Ireland.

Contributors JM: patient care, data acquisition, manuscript drafting and revision. KAJS: patient care, manuscript drafting and revision. EH: manuscript drafting and revision. CCM: patient care, manuscript drafting and revision.
Funding The authors have not declared a specific grant for this research from any funding agency in the public, commercial or not-for-profit sectors.

Competing interests None declared.

Patient consent for publication Not required.

Provenance and peer review Not commissioned; externally peer reviewed.

ORCID iD

Kirk A J Stephenson http://orcid.org/0000-0002-7462-7725

\section{REFERENCES}

1 Hu Y, Huang Z, Yang S, et al. Effectiveness and safety of anti-tumor necrosis factoralpha agents treatment in Behcets' disease-associated uveitis: a systematic review and meta-analysis. Front Pharmacol 2020;11:941.

2 Hosseini SM, Shoeibi N, Ebrahimi R, et al. Patterns of uveitis at a tertiary referral center in northeastern Iran. J Ophthalmic Vis Res 2018;13:138.

3 Somkijrungroj T, Vongkulsiri S, Kongwattananon W, et al. Assessment of vascular change using swept-source optical coherence tomography angiography: a new theory explains central visual loss in Behcet's disease. J Ophthalmol 2017;2017:1-6.

4 Davatchi F, Chams-Davatchi C, Shams H, et al. Behcet's disease: epidemiology, clinical manifestations, and diagnosis. Expert Rev Clin Immunol 2017;13:57-65.

5 Alpsoy E. Behçet's disease: a comprehensive review with a focus on epidemiology, etiology and clinical features, and management of mucocutaneous lesions. J Dermatol 2016;43:620-32

6 Nair JR, Moots RJ. Behcet's disease. Clin Med 2017;17:71-7.

7 Hussein MA, Eissa IM, Dahab AA. Vision-threatening Behcet's disease: severity of ocular involvement predictors. J Ophthalmol 2018;2018:1-6.

8 Bowling B. Kanski's clinical ophthalmology. 8th edn. London United Kingdom: Elsevier, 2015: 281.

9 Hatemi G, Christensen R, Bang D, et al. 2018 update of the EULAR recommendations for the management of Behçet's syndrome. Ann Rheum Dis 2018;77:808-18.

10 Saleh Z, Arayssi T. Update on the therapy of Behçet disease. Ther Adv Chronic Dis 2014;5:112-34.

11 Ozguler $Y$, Leccese $P$, Christensen $R$, et al. Management of major organ involvement of Behçet's syndrome: a systematic review for update of the EULAR recommendations. Rheumatology 2018;57:2200-12.

12 Taylor SRJ, Singh J, Menezo V, et al. Behçet disease: visual prognosis and factors influencing the development of visual loss. Am J Ophthalmol 2011;152:1059-66.

Copyright 2021 BMJ Publishing Group. All rights reserved. For permission to reuse any of this content visit

https://www.bmj.com/company/products-services/rights-and-licensing/permissions/

BMJ Case Report Fellows may re-use this article for personal use and teaching without any further permission.

Become a Fellow of BMJ Case Reports today and you can:

- Submit as many cases as you like

- Enjoy fast sympathetic peer review and rapid publication of accepted articles

- Access all the published articles

- Re-use any of the published material for personal use and teaching without further permission

Customer Service

If you have any further queries about your subscription, please contact our customer services team on +44 (0) 2071111105 or via email at support@bmj.com.

Visit casereports.bmj.com for more articles like this and to become a Fellow 